\title{
Karabağlar (İzmir) Bölgesindeki Heyelanların Olası Yenilme Koşulları
}

\author{
Possible Failure Conditions of the Landslides in Karabağlar (İzmir) \\ Koray ULAMIŞ* $\mathbb{D}$, Recep KILIÇ (D) \\ Ankara Üniversitesi, Mühendislik Fakültesi, Jeoloji Mühendisliği Bölümü, 06830, Ankara
}

Geliş (Received): 02 Ağustos (August) 2019 / Düzeltme (Revised): 20 Eylül (September) 2019 / Kabul (Accepted): 17 Ekim (October) 2019

\section{ÖZ}

Kentleşmede doğal afet potansiyelinin ve olas1 etkilerinin önceden belirlenmesi önem arz etmektedir. Ülkemizde en sık görülen afetlerden olan heyelan, mühendislik yapılarını ve çevreyi olumsuz etkilemektedir. Bu çalışmada, İzmir ili, Karabağlar ilçesi sınırlarındaki heyelanların mühendislik jeolojisi özellikleri incelenerek, yenilme kriterleri değerlendirilmiştir. İnceleme alanında Üst Kretase yaşlı Bornova Karmaşığı üzerinde uyumsuz Miyosen yaşlı killi kireçtaşı ile Kuvaterner yamaç molozu bulunmaktadır. Arazide heyelanların boyutları belirlenerek, kayma yüzeyi derinlikleri ile yeraltı suyu seviyesini ölçmek için derinlikleri $10.0 \mathrm{~m}$ ile $35.0 \mathrm{~m}$ arasında değișen 52 adet sondaj yapılmıştır. İnceleme alanını oluşturan Şamlı Tepe'nin güney, batı ve kuzey kesimlerinde toplam 58 adet heyelan belirlenmiş̧ir. Heyelanlar, Miyosen yaşlı karbonatlı seviyeler ile çakıl, kum ve silt mercekleri bulunduran kil içerisinde gelişmiştir. Heyelanların kabarma ve akma bölgelerinde daha küçük boyutlu çok sayıda ikincil yenilmeler mevcuttur. Heyelanlarda geriye dönük analizler yapılarak limit denge şartlarındaki rezidüel içsel sürtünme açısı ve rezidüel kohezyon belirlenmiştir. Şamlı Tepe ve güneyindeki yol kazısında geçmişte topuktan yük alınması ve K-G doğrultulu dere yatağının aşındırması ile düşük kotlarda başlayan yenilmeler kuzeye doğru gerileyerek daha büyük çaptaki heyelanı tetiklemiştir. Şevlerde statik koşul yanında inceleme alanının depremselliği de dikkate alınarak psödostatik analizler yapılmıştır. Güvenlik katsayısı ile psödostatik katsayı ilişkisi incelenerek, analizlerde limit denge koşulunu sağlayan katsayı 0.10 olarak belirlenmiştir. Elde edilen değer inceleme alanı ve çevresindeki en büyük yatay yer ivmesi ile beraber değerlendirildiğinde ileride yapılacak şev duraylılı̆̆ çalışmalarında kullanılabilecek niteliktedir.

Anahtar Kelimeler: Karabağlar, Heyelan, Stabilite, Psödostatik katsayı, Güvenlik katsayısı

\begin{abstract}
Determination of the natural hazard potential and possible effects on urbanization is a key factor. Landslide is the most prominent hazard in Turkey, causing adverse effects on the engineering structures and environment. This study aims to investigate the engineering geological investigation and failure criteria of the landslides which took place in Karabağlar district of İzmir. Upper Cretaceous aged Bornova Mélange is unconformably overlain by Miocene aged clayey limestone and Quaternary aged alluvium. The dimensions of the landslides were determined. A total of 52 boreholes with depths ranging between $10 \mathrm{~m}$ and $35 \mathrm{~m}$ were drilled in order to obtain the sliding depth and groundwater level. There existed 58 landslides around the southern, western and northern parts of the Samlı hill. Landslides took place mainly in the Miocene aged clay and carbonates with gravel, sand and silt lenses. Secondary minor slides have occurred in the depletion and accumulation zones. Back analyses were conducted to attain the residual internal friction angle and residual cohesion which provided limit equilibrium. The main slide has been triggered by the minor failures which have taken place at lower elevations, being retrogressive to north. Main reasons of these slides are the road excavation at the south and carving of the creek which flows in N-S direction. Static and pseudo-static slope stability analyses were done with particular concern in the seismicity of the region.
\end{abstract}


Ulamış, Kılıç

The relation between the factor of safety and pseudo-static coefficient was investigated. The pseudo-static coefficient at limit equilibrium was determined as 0.10. This value should be taken into account with peak ground acceleration for the future slope stability investigations for the study area and its vicinity.

Keywords: Karabağlar, Landslide, Stability, Pseudostatic coefficient, Factor of safety

\section{GÍRIŞ}

Heyelanların incelenmesi ve gerekli önlemlerin önceden alınması yer seçiminde önemli bir faktördür. Heyelanları tetikleyen unsurlar deprem ve aşırı yağışlar (Cruden ve Fell, 1997) ile nüfus artışına paralel olarak gelişen hızlı ve plansız yapılaşmalardır (Schuster, 1996). Heyelan kavramı teknik olarak ilk defa Onions vd. (1933) tarafından kullanılmış olup, farklı araştırmacılar ve kurumlar tarafindan detaylı olarak açıklanmıştır (Cruden, 1991; IAEG, 1990; WP/WLI, 1993; Varnes, 1978; Cruden ve Fell, 1997; Hungr vd., 2014). Heyelan oluşum mekanizması, duraylılık analizi ve iyileştirme yöntemleri ile ilgili bir çok çalışma yapılmıştır (Fellenius, 1927; Bishop, 1955; Lowe ve Karafiath, 1960; Morgenstern ve Price, 1965; Spencer, 1967; Janbu, 1968; US Army of Corps, 1970; Sarma, 1973).

Kıncal vd. (2009), İzmir şehir merkezi ve çevresi için heyelan hassasiyet haritası üretmişlerdir. Tarcan ve Koca (2000), İzmir ili, Kadifekale civarındaki heyelanların jeoteknik ve hidrojeolojik incelemesini yapmıştır. İller Bankası Genel Müdürlüğü'nün 1994 yılında hazırlamış olduğu "Uzundere-İzmir Belediyesi İmar Planına Esas Jeolojik Etüd Raporu"nda Karabağlar bölgesinin kireçtaşı ve marndan oluştuğunu belirtmiş, mevcut ve muhtemel heyelan nedeni ile "Afete Maruz Bölge" olarak tanımlamıştır. İzmir ili, Karabağlar ilçesi sınırları içinde Şamlı Tepe ve çevresindeki alan, heyelanlar nedeni ile 6306 say1lı kanun kapsamında 2012 yılında Bakanlar Kurulu kararı ile "Yapılaşma Riskli Alan" ilan edilmiştir. İnceleme alanında heyelanların mühendislik jeolojisi konusunda herhangi bir çalışmaya rastlanılmamıştır. İzmir ili, Karabağlar İlçesi’nde (Şekil 1) heyelanların sinıflaması (Varnes, 1984), boyutları ve oluşum mekanizmaları arazi gözlemleri, jeoteknik amaçlı sondajlar ve jeofizik yöntemlerle incelenerek mühendislik jeolojisi haritası hazırlanmıştır (Kılıç, 2013). Heyelanların statik ve dinamik koşullarda duraylılık analizleri yapılmış ve limit denge koşulunu veren ideal psödostatik katsayı belirlenmiștir.



Şekil 1. İnceleme alanı yer bulduru haritası ve belirgin heyelanların görüntüsü.

Figure 1. Location map of the study area and significant landslides. 


\section{JEOLOJI}

İnceleme alanı ve çevresinde temel birimler Paleozoyik yaşlı gnays ve şistler (Şengör vd., 1984) olup, üzerlerine tektonik dokanakla Üst Kretase-Paleosen yaşlı Bornova Karmaşığ gelir (Erdoğan, 1990). Bu birimlerin üzerine açısal uyumsuz Alt Miyosen-Erken Pliyosen yaşlı kireçtaşı ve marn gelmektedir (Yılmaz vd. 2000; Genç vd. 2001). İnceleme alanını çevreleyen dere yataklarında alüvyon ile güneyde Uzundere yatağı civarında kalınlığ 1 1.0-7.0 m. arasında değişen dolgu yer alır (Kılıç, 2013). İzmir fayı eğim atımlı normal bir fay olup, Holosen'de yüzey yırtılmasıyla sonuçlanan büyük depremlere kaynaklık etmiştir. Tuzla fayı, İzmir' in güneybatısında Gaziemir ile Doğanbey arasında KD-GB genel uzanımlı sağ yanal doğrultu atımlı fay karakterindedir (Emre vd. 2005). İnceleme alanı, İzmir fay1 ve Tuzla Fay Zonu arasında kalan dar bir alanda basınç sırtı niteliğinde gelişmiştir.

\section{ARAZİ ÇALIŞMALARI}

İnceleme alanındaki heyelanların konumları, arazinin en belirgin yükseltisi olan Şamlı Tepe (204 m)' nin güney, batı ve kuzey yamacındakiler ayrılarak incelenmiştir (Şekil $2 \mathrm{a}$ ve $2 \mathrm{~b}$ ). Heyelanların boyutlarını belirlemek, birimlerin yatay ve düşey yöndeki değişimlerini belirlemek ve temsil edici örnekler almak, sık1lık ve kıvamını belirlemek amacı ile derinlikleri $10 \mathrm{~m}$ ile $35 \mathrm{~m}$ arasında değişen 52 adet sondaj çalışması gerçekleştirilmiştir (Altundağ, 2013). Sondaj kuyularına plastik borular yerleştirilerek yeraltı suyu seviyeleri ölçülmüştür. Heyelanlar üzerinde sondaj yapılamayan yerlerde açılan 9 adet $3.5 \mathrm{~m}$ derinliğinde $\mathrm{AÇ}$ simgesi ile gösterilen araştırma çukurlarından (Şekil 3) kayma yüzeyindeki zeminlerden kesme kutusu deneyleri için örselenmemiş örnekler alınmıştır.

\section{HEYELANLARIN MORFOLOJISİ VE JEOTEKNIK ÖZELLİKLERİ}

İnceleme alanında Miyosen yaşlı karbonatlı seviyeler ile çakıl ve kum mercekleri içeren killerde irili ufakl1 58 adet heyelanın meydana geldiği belirlenmiştir. Karbonatlı seviyeler genelde yüksek kotlarda olup, bu seviyelerin altındaki doygun killerden itibaren kaymalar gerçekleşmiştir. İnceleme döneminde yeraltı suyu seviyesi $1.0 \mathrm{~m}$ ile $7.5 \mathrm{~m}$ arasında değişmektedir. Şamlı tepenin güneyindeki eğimler \%15-20 arasında, kuzeyindeki eğim \%14-18 arasında ve batısındaki eğim \%17-22 arasında değişmektedir (Şekil 2a ve Şekil 3). Şamlı Tepe'nin güneydeki yenilmeler alt kotlardan başlayarak kuzeye doğru ilerlemiş, heyelanın uzunluğu ve genişliğini artırmış ve daha geniş alanları etkilemiştir. Güney yamaçtaki en büyük heyelanın uzunluğu $600 \mathrm{~m}$, genişliği $450 \mathrm{~m}$ ve kayma derinliği en çok 20 m'dir. Batı yamaçtaki heyelanların kayma derinlikleri $9.0 \mathrm{~m}$ ile $13.0 \mathrm{~m}$, kuzey yamaçtaki heyelanların kayma derinliği ise $7.0 \mathrm{~m}$ ile $10.0 \mathrm{~m}$ arasında değişmektedir. Kayma derinliklerinin belirlenmesinde sondajlar ve jeofizik hatlar ile sismik kesit hatlarından yararlanılmıştır. Ayrıca, heyelan aynası belirgin olan kaymalarda kayma dairesi ve konsantrik daire yöntemleri ile kayma derinlikleri belirlenmiştir. İnceleme alanının 1/1000 ölçekli topoğrafik harita üzerine işlenmiş Şekil 3'teki mühendislik jeoloji haritasında sondaj numaraları ve yeri, esas heyelan aynaları, heyelan gölleri ve duraylılık analizleri için belirlenen kesit hatları ile sismik kesit hatları gösterilmiştir. Kesit hatları arazinin morfolojisi ve heyelan geometrisini en ideal şekilde yansıtacak şekilde belirlenmiştir. Ayrıca, arazide belirlenebilen heyelan gölü, su çıkış noktaları, ikincil yenilmelerin konumları ve heyelana bağlı gelişen topoğrafik bozukluklar da dikkate alınmıştır. 
Ulamış, Kılıç


Şekil 2. Heyelanın güney yamacının görünüşü (a) ve batı yamacındaki kumtaşlarının üzerinde kaydığı kilin görünüşü (b).

Figure 2. View of the south slope of the landslides (a) and the clay sliding on the sandstones in the western slope (b). 


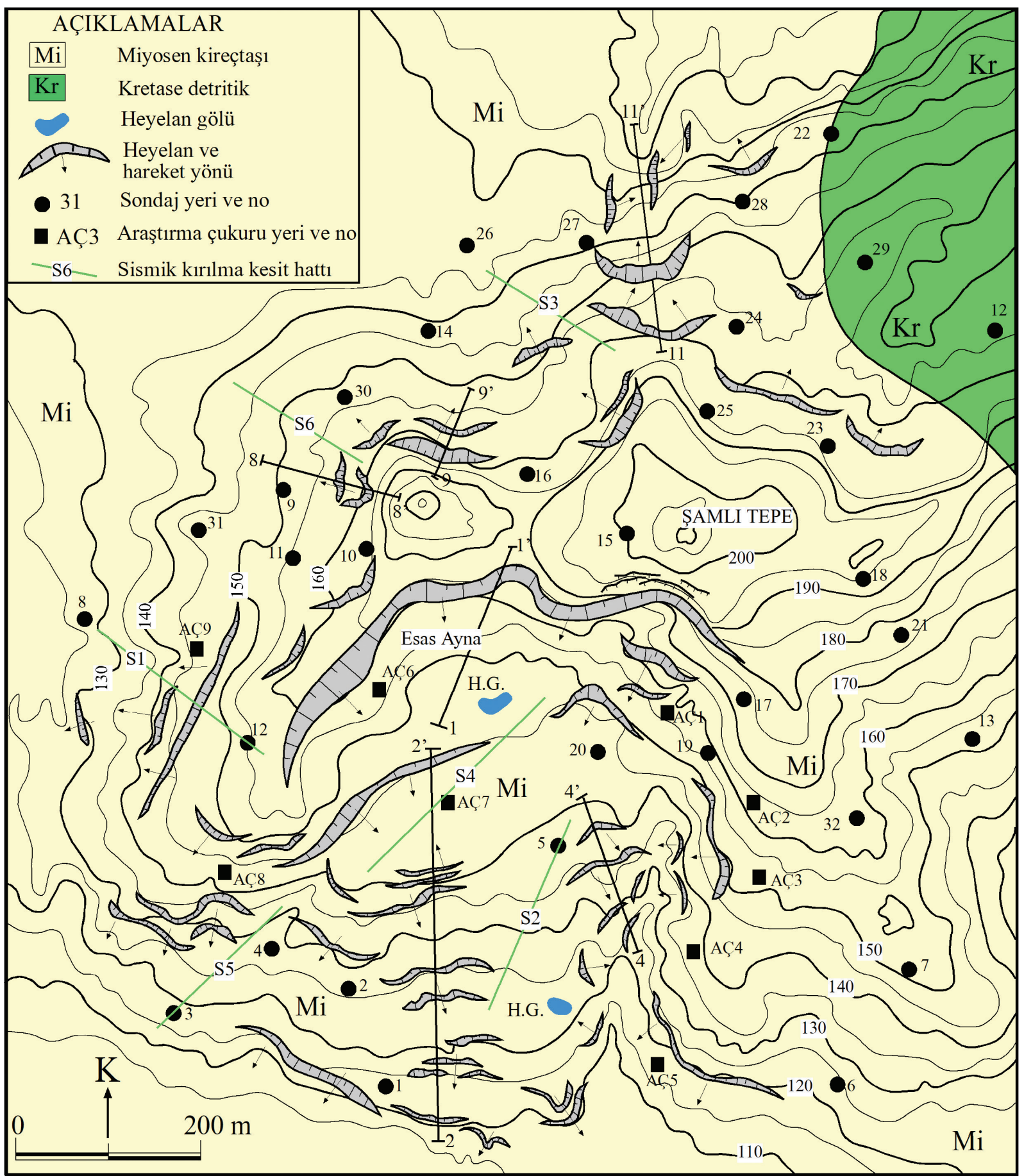

Şekil 3. İnceleme alanının mühendislik jeolojisi haritası ve heyelanların konumları.

Figure 3. Engineering geological map of the study area and landslide locations. 
Ulamış, Kılıç

Sondajlar ve araştırma çukurlarından alınan kayma düzlemindeki killerin doğal su içeriği, tane boyu dağılımı, kıvam limitleri, doğal birim ağırlığı belirlenerek sınıflaması TS 1900-1 (2006)'e göre yapılmış, örselenmemiş örneklerde doruk ve artı makaslama parametreleri konsolidasyonlu-drenajsız (CU) şartlarda ASTM D5628-17 (2017) standardına göre belirlenmiştir. Elde edilen sonuçlar Çizelge 1'de verilmiştir (K1lıç, 2013). yapılan geriye dönük analizlerde yenilmenin gerçekleştiği şevlerde güvenlik sayısı 1.006 ile 1.097 arasında değişmektedir. Geriye dönük analiz ile halihazırda laboratuvarda belirlenen makaslama parametreleri karşılaştırıldığında, kayma düzlemindeki killerin artık kohezyon değerlerininönemliölçüde azaldığı belirlenmiştir. Şamlı Tepe güneyi, kuzeyi ve batısındaki kesit hatlarında limit denge koşulunu sağlayan (GS=1.0) statik ve psödostatik analizlerden elde edilen makaslama parametreleri, ile kayma

Çizelge 1. Heyelanın kayma yüzeyindeki CL ve CH grubu killerin indeks özellikleri ile artık makaslama dayanım parametreleri.

Table 1. Index properties and the residual shear strength parameters of the CL and CH soils obtained from the sliding surface of the landslide.

\begin{tabular}{ccccccccc}
\hline$\omega_{\mathrm{n}}, \%$ & $\gamma_{\mathrm{n}}, \mathrm{kN} / \mathrm{m}^{3}$ & $+4 \#$ elek & $-200 \#$ elek & LL, $\%$ & PL, $\%$ & PI, $\%$ & $\mathrm{c}^{\prime}, \mathrm{kPa}$ & $\phi^{\prime \circ}$ \\
\hline 17 & 18.22 & 2.0 & 73.1 & 53.8 & 28.6 & 25.2 & 33 & 10 \\
\hline 20 & 18.26 & 0.9 & 86.8 & 60.8 & 28.4 & 32.4 & 39 & 8 \\
\hline 18 & 18.12 & 3.6 & 64.8 & 51.0 & 25.5 & 25.5 & 30 & 9 \\
\hline 25 & 17.89 & 0.8 & 77.6 & 40.8 & 22.1 & 18.7 & 28 & 9 \\
\hline 11 & 18.05 & 4.6 & 60.2 & 37.8 & 19.3 & 18.5 & 34 & 9 \\
\hline 20 & 18.31 & 0.6 & 87.3 & 32.5 & 16.1 & 16.4 & 33 & 11 \\
\hline 21 & 18.23 & 0.7 & 73.9 & 57.1 & 26.5 & 30.6 & 20 & 7 \\
\hline
\end{tabular}

\section{ŞEV DURAYLILIK ANALIZLERİ}

İnceleme alanındaki heyelanlarda duraylil1k analizleri statik ve psödostatik koşulda geriye dönük yapılarak limit denge koşulunu sağlayan artık kohezyon ve artık içsel sürtünme açıları belirlenmiştir. Laboratuvar deneylerinden elde edilen artık makaslama parametrelerine göre yapılan şev duraylılık analizlerinde şevlerin duraylı olduğu belirlenmiştir. Statik şartlarda düzlemi derinlikleri Çizelge 2'de verilmiştir. Şekil 4'te mühendislik jeolojisi haritasındaki 1-1' numaralı kesit hattındaki statik duraylılık analizi verilmiştir. Analizler dairesel yenilmeyi esas alan ve hem sı̆̆ hem de derindeki kaymalar için güvenilir sonuçlar veren Bishop (1955) yöntemine göre Slide $6.0 \AA$ programı kullanılarak yapılmıştır. Arazi gözlemleri, sondaj ve jeofizik veriler değerlendirildiğine yenilmeler dairesel düzlemde gelişmiştir. 
Çizelge 2. Kesit hatlarındaki geri analiz ile belirlenen güvenlik sayıları ile kayma derinlikleri.

Table 2. Factor of safety derived from back analyses and sliding depths relevant to the cross-sections.

\begin{tabular}{cccccccc}
\hline $\begin{array}{c}\text { Kesit } \\
\text { Hatt1 }\end{array}$ & $\begin{array}{c}\mathrm{c}_{\mathrm{r}}^{\prime} \\
(\mathrm{kPa})\end{array}$ & $\begin{array}{c}\phi_{\mathrm{r}}^{\prime} \\
\left({ }^{\prime}\right)\end{array}$ & $\begin{array}{c}\gamma_{\mathrm{n}} \\
\left(\mathrm{kN} / \mathrm{m}^{3}\right)\end{array}$ & $\begin{array}{c}\gamma_{\text {sat }} \\
\left(\mathrm{kN} / \mathrm{m}^{3}\right)\end{array}$ & $\begin{array}{c}\text { GS } \\
(\text { statik })\end{array}$ & $\begin{array}{c}\text { GS } \\
(\text { psödostatik })\end{array}$ & $\begin{array}{c}\mathrm{h} \\
(\mathrm{m})\end{array}$ \\
\hline $1-1^{\prime}$ & 15 & 10 & 17.9 & 18.9 & 1.050 & 0.978 & 15 \\
\hline $2-2^{\prime}$ & 16 & 4 & 18.5 & 19.8 & 1.049 & 0.936 & 11 \\
\hline $4-4^{\prime}$ & 16 & 4 & 18.9 & 19.5 & 1.097 & 0.894 & 16 \\
\hline $8-8^{\prime}$ & 18 & 5 & 18.0 & 19.2 & 1.006 & 0.925 & 13 \\
\hline $9-9^{\prime}$ & 14 & 8 & 18.2 & 19.0 & 1.060 & 0.969 & 9 \\
\hline $11-11^{\prime}$ & 23 & 8 & 18.0 & 18.8 & 1.071 & 0.988 & 14 \\
\hline
\end{tabular}

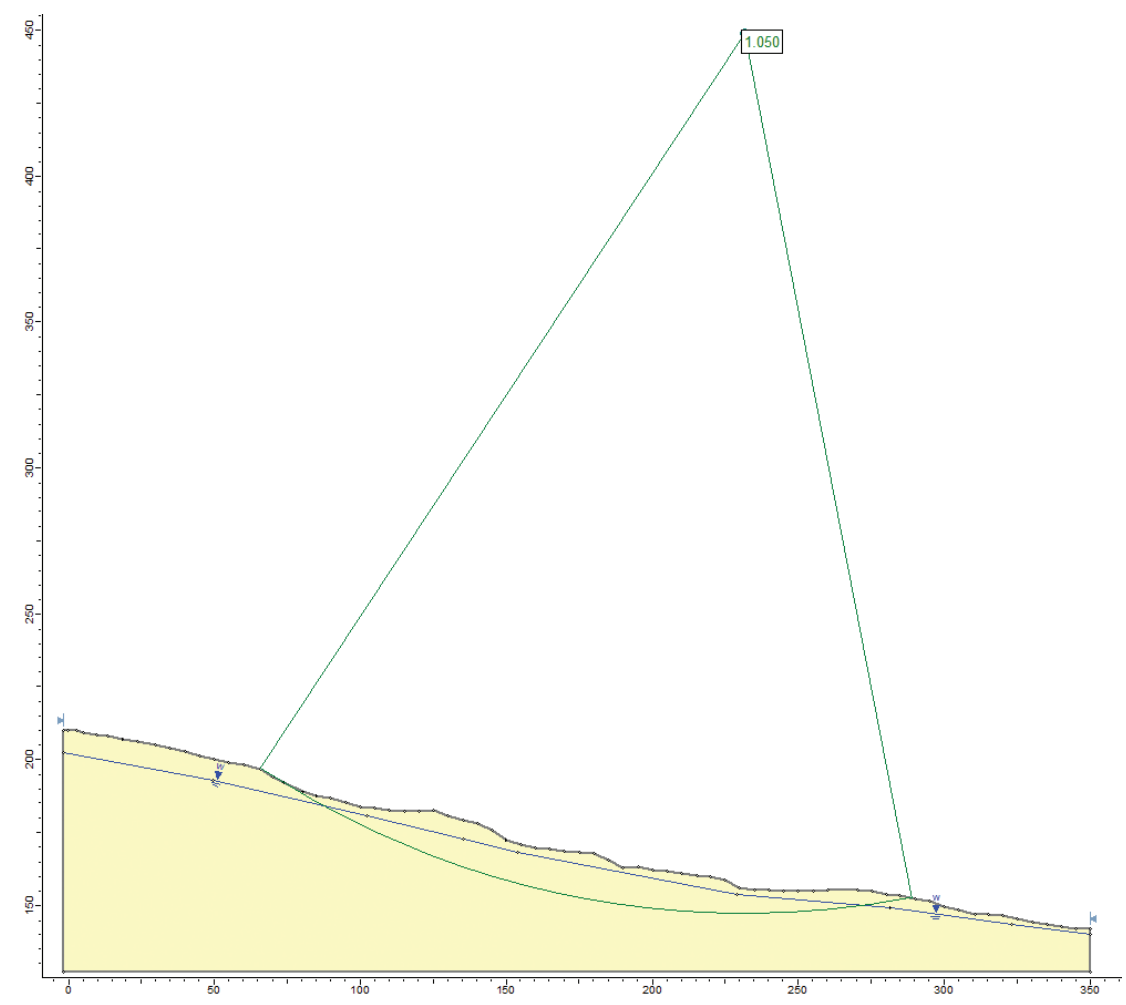

Şekil 4. 1-1' kesit hattındaki heyelanın statik şartlarda kayma dairesi ve güvenlik sayısı.

Figure 4. Sliding surface and factor of safety of the landslide on 1-1'cross-section under static conditions.

Çizelge 2'de statik koşulda 4-4' kesit hattı ve 11-11' kesit hattındaki güvenlik sayıları 1.1'e yakındır. Her iki kesit hattındaki yenilmeler esas heyelana göre (1-1' hattındaki heyelan) daha düşük eğimde ve tali yenilmeler olarak gelişmiştir. 
Ulamış, Kılıç

Geri analizlerde heyelan geometrisini ideal şekilde temsil eden 6 adet kesit hattında belirlenen artık kohezyon $18 \mathrm{kPa}$, artık içsel sürtünme aç1sı $4^{\circ}$ olarak belirlenmiştir (Şekil 5). Psödostatik analiz yönteminde (Terzaghi, 1950) psödostatik katsayının $\left(\mathrm{k}_{\mathrm{h}}\right)$ belirlenmesi önemli rol oynamaktadır. Yenilme esnasında kütle rijit kalmayacağından, etkiyen pik ivme kayan kütleye kısa süreli etki eder. Dolayısıyla; başlangıç pik ivmenin şev duraylılık analizlerinde kullanılması güvenlik sayısında normal olmayan azalmalara neden olacaktır (Seed, 1979; Kramer, 1996). sayılarının standart sapmaya göre değişim aralıkları Şekil 6'da verilmiştir. İki parametre arasında yapılan kikare analizine göre aralarında $\% 95$ anlaml1lik seviyesinde lineer ters orant1 bulunduğu belirlenmiştir. Güvenlik katsayısı, psödostatik katsayının 0.01 ile 0.2 arasındaki değerleri arttıkça azalmaktadır. Eşitlik 1'de inceleme alanında duraylılık analizi yapılan kesit hatlarında genelleştirilmiş güvenlik sayısı ile psödostatik katsayı ilişskisi verilmiştir.

$\mathrm{GS}=1.2-2.8764 \mathrm{xk}_{\mathrm{h}} \quad\left(\mathrm{R}^{2}=0.968\right)$

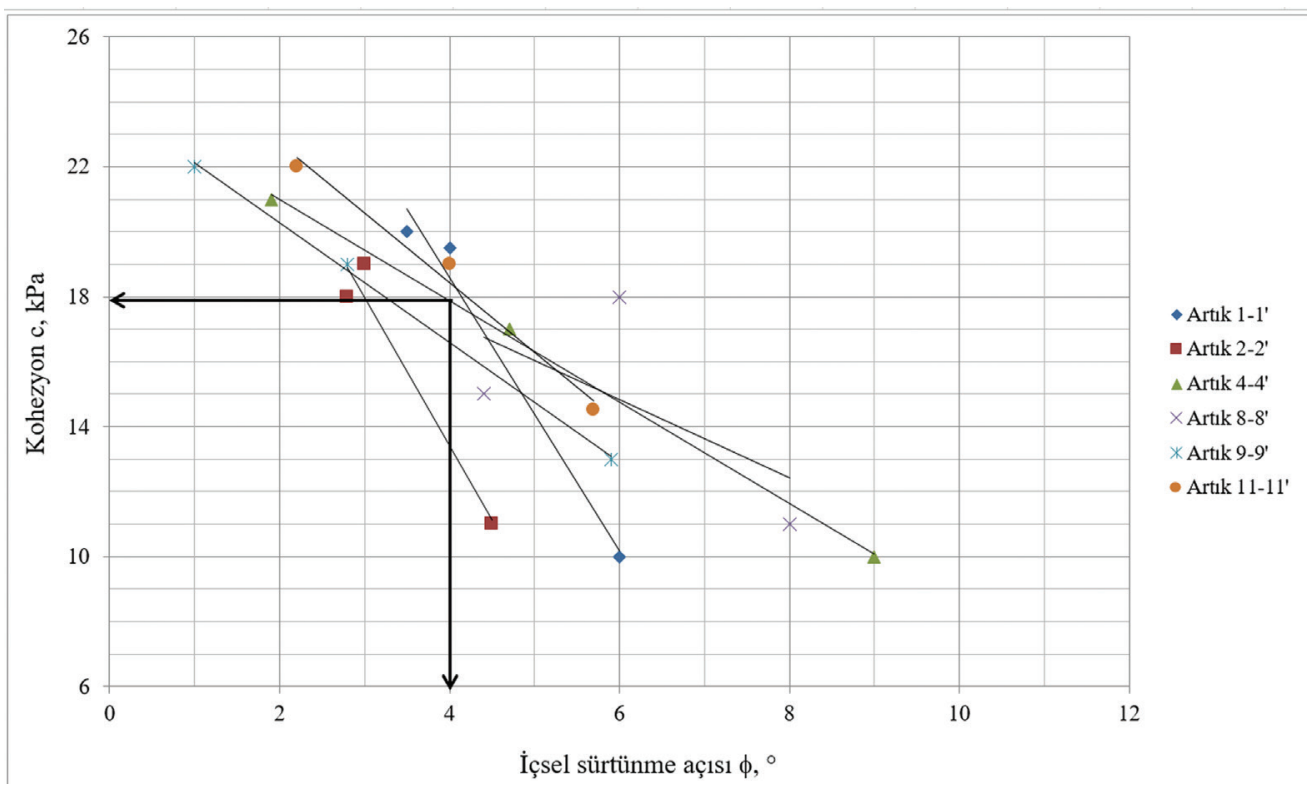

Şekil 5. Kesit hatlarında statik koşulda geri analizden elde edilen artık makaslama dayanım parametreleri.

Figure 5. Residual shear strength parameters determined from the back analyses of cross sections under static conditions.

Psödostatik katsayının duraylılık analizlerinde kullanılması ve dizayn deprem büyüklügüne göre belirlenmesi ile ilgili çalışmalar yapılmıştır (Seed, 1979; Kramer, 1996; Melo ve Sharma, 2004; Jibson, 2011). Duraylı1ık analizlerinden belirlenen güvenlik sayıları (GS) ile psödostatik katsayılar $\left(\mathrm{k}_{\mathrm{h}}\right)$ arasındaki ilişki incelenerek, güvenlik
Türkiye Deprem Tehlike Haritası (AFAD, 2018) kullanılarak inceleme alanı için belirlenen en büyük yatay yerivmesi $0.454 \mathrm{~g}$ olup, psödostatik analizlerde kullanılması önerilen ilişkiler de dikkate alınarak (Çizelge 3) inceleme alanındaki duraylılık analizlerinde psödostatik katsayının 0.10 olarak kabul edilmesi uygun görülmüştür. Daha yüksek katsayı değerlerinde güvenlik sayısı 




Şekil 6. Güvenlik katsayısı ile psödostatik katsayı ilişkisi.

Figure 6. Relation between the factor of safety and pseudostatic coefficient.

Çizelge 3. Psödostatik katsayı ile ilgili çalışmalar ve öneriler.

Table 3. Previous work about the pseudostatic coefficient and recommendations.

\begin{tabular}{|c|c|}
\hline $\mathrm{k}_{\mathrm{h}}$ & Açılama \\
\hline $0.05-0.15$ & $\mathrm{ABD}$ \\
\hline $0.12-0.25$ & Japonya \\
\hline 0.1 & $\begin{array}{l}\text { Büyük } \\
\text { depremler, } \\
\text { IX }<\text { RF }<X\end{array}$ \\
\hline 0.2 & Y1kıcı depremler \\
\hline 0.5 & $\begin{array}{l}\text { Katastrofik } \\
\text { depremler }\end{array}$ \\
\hline $0.1-0.2$ & $\begin{array}{l}\text { Seed }(1979) \mathrm{GS} \geq 1.15, \mathrm{M}=6.5 \text { ile } \\
8.25 \text { arasinda }\end{array}$ \\
\hline 0.10 & $\begin{array}{l}\text { Corps of Eng. } \\
\text { (1982) }\end{array}$ \\
\hline 0.15 & $\begin{array}{l}\text { Çok büyük } \\
\text { depremler }\end{array}$ \\
\hline $1 / 2-1 / 3$ pga & $\begin{array}{l}\text { Marcuson ve Franklin (1983), } \\
\text { GS }>1.0\end{array}$ \\
\hline $1 / 2 \mathrm{pga}$ & $\begin{array}{l}\text { Hynes-Griffin ve Franklin (1984), } \\
\text { GS }>1.0\end{array}$ \\
\hline
\end{tabular}

0.75-0.80 aralığında kalmaktadır. İnceleme alanı Uzel ve Sözbilir (2008) tarafından tanımlanmış olan İzmir-Balıkesir Transfer Zonu içerisinde yer almakta olup, bir çok farklı türde faylar ile sınırlandırılmıştır. Aletsel dönemde büyüklüğü $5.0^{`}$ den büyük 14 adet deprem kaydedilmiștir (Emre vd., 2005). Neotektonik fayların konumlar1, ürettikleri depremler ve inceleme alanının aktif bir zon içinde olması nedeni ile psödostatik analizler yapılmıştır.

\section{SONUÇ VE ÖNERILLER}

İnceleme alanında Miyosen yaşlı killerin içinde güneyde yapılan yol kazısına bağlı topuktan yük alınması ve G-K doğrultudaki dere yatağının mevsimsel su taşımasına bağlı olarak aşındırması sonucunda farklı büyüklüklerde heyelanlar gelişmiştir. Kil üzerindeki ayrışmış kireçtaşı, kumtaşı ve bunların üzerindeki yamaç molozu kaymaktadır. 
İnceleme alanının güney yamacında eğim $\% 15$ ile $\% 18$ arasında değişmektedir. Tali yolun yamacında ise eğim \%23'e varmaktadır. Şamlı Tepe'de başlayan ve güney yamaçta yer alan en büyük heyelanın içinde ikincil yenilmeler belirlenmiştir. Kuzeye doğru (esas heyalan aynası) yenilmeler geliştikçe eğim azalarak geriye doğru ilerleyen türde bir heyelan gelişmiştir.

Kayma düzlemindeki killerden alınan örneklerde CU kesme kutusu deneyleri yapılmış olup, elde edilen artık makaslama parametrelerine göre şevler duraylıdır. Hareketin durakladığı heyelanlarda kayma düzlemindeki killi zemin hareket öncesindeki limit denge koşuluna göre göreceli olarak yüksek kohezyona sahip olacaktır.

Heyelanların yenilme koşulunu daha doğru ifade edebilmek için geriye dönük analizler yapılmıştır. Analizler sonucunda statik koşulda artık kohezyon büyük ölçüde azalmış olup, yenilmenin kohezyon tarafindan kontrol edildiği belirlenmiştir.

İnceleme alanının Ege Bölgesi horst-graben sistemi içinde bulunması, yakın çevresindeki faylar ve depremselliği de dikkate alınarak psödostatik analizler gerçekleştirilmiştir. Kesit hatları için güvenlik sayısı ile psödostatik katsayı ilişkisi incelenerek, inceleme alanındaki heyelanlarda kullanılabilecek psödostatik katsayı belirlenmiştir.

İnceleme alanında yapılaşmaya izin verilebilmesi için detaylı jeoteknik inceleme yapılması ve heyelanların çevreye ve gelecekte planlanacak yapılara zarar vermesinin önlenmesi için gerekli iyileştime yöntemlerinin dinamik şartlarda analizleri yapılarak belirlenmesi ve projelendirilmesi gerekmektedir.

\section{KAYNAKLAR}

AFAD, 2018. Türkiye deprem tehlike haritas1, interaktif web uygulamasi. (https://tdth.afad.gov. tr/TDTH/main.xhtml. Ziyaret tarihi: 12.09.2019)

Altundağ, E., 2013. İzmir ili, Karabağlar ilçesi, 540 hektarlık alanın 1/1.000 ölçekli imar planına esas jeolojik-jeoteknik etüd raporu, $241 \mathrm{~s}$.

ASTM D6528-17, 2017. Standard test method for consolidated undrained direct shear testing of fine grained soils. ASTM International, West Conshohocken, PA.

Bishop, A. W., 1955. The use of slip circle in the stability analysis of earth slopes. Geotechnique, 5(1), 7-17.

Corps of Engineers, 1982. Slope stability manual EM1110-2-1902. Washington DC, Department of the Army, Office of the Chief of Engineers.

Cruden, D.M., 1991. A simple definition of a landslide. Bulletin International Assocication Engineering Geology, 43, 27-30.

Cruden, D.M., Fell, R., 1997. Workshop on landslide assessment. Proc. Int. Workshop on Landslide Risk Assessment, Hawaii, USA, 371p.

Emre, Ö., Özalp, S., Doğan, A., Özaksoy, V., Yıldırım, C., Göktaş, F., 2005. İzmir yakın çevresinin diri fayları ve deprem potansiyelleri. MTA Raporu, 10754, $86 \mathrm{~s}$.

Erdoğan, B., 1990. İzmir-Ankara Zonu'nun İzmir ile Seferihisar arasindaki bölgede stratigrafik özellikleri ve tektonik evrimi. TPJD Bülteni, 2, $20 \mathrm{~s}$.

Fellenius, W., 1927. Erdstatische Berechnungen mit Reibung und Kohäsion (Adhäsion) und unter Annahme kreiszylindrischer Gleitflächen"Ernst \& Sohn, Berlin.

Genç, S.C., Altunkaynak, S., Karacik, Z., Yazman, M., Yılmaz, Y., 2001. The Çubukludag graben, south of Izmir: tectonic significance in the Neogene geological evolution of the Western Anatolia. Geodinamica Acta, 14, 1-12.

Hungr, O., Leroueli, S., Picarelli, L., 2014. The Varnes classification of landslide types, an update. Landslides, 11, 167-194. 
Hynes-Griffin M.E., Franklin A.G., 1984. Rationalizing the seismic coefficient method. U.S. Army Corps of Engineers Waterways Experiment Station, Vicksburg, Mississippi, GL84-13, $21 \mathrm{p}$.

IAEG Commission on Landslides, 1990. Suggested nomenclature for landslides. Bulletin of International Association of Engineering Geology, 41, 13-16.

Janbu, N., 1968. Slope stability computations. Soil Mechanics and Foundation Engineering, Technical University of Norway.

Jibson, R.W., 2011. Methods for assessing the stability of slopes during earthquakes, a retrospective. Engineering Geology, 122, 43-50.

Kılıç, R., 2013. İzmir İli, Karabağlar Bölgesindeki heyelanların ve duraylılığının incelenmesine ait jeoteknik rapor, $40 \mathrm{~s}$.

Kincal, C., Akgün, A., Koca, M.Y., 2009. Landslide susceptibility assessment in the İzmir (West Anatolia, Turkey) city center and its near vicinity by the logistic regression method. Environmental Earth Sciences, 59, 745-756.

Kramer S.L.,1996. Geotechnical earthquake engineering. Prentice-Hall, Inc., Upper Saddle River, NJ, 653 p.

Lowe, J., Karafiath, L., 1960. Stability of earth dams upon drawdown. 1st Pan American Conference on Soil Mechanics and Foundation Engineering, Mexico City, 2, 537-552.

Marcuson W.F, Franklin A.G, 1983. Seismic design, analysis and remedial measures to improve the stability of existing earth dams - Corps of Engineers approach. Seismic Design of Embankments and Caverns, T.R. Howard, Ed., NY, ASCE.

Melo, C. and Sharma, S., 2004. Seismic coefficients for pseudostatic analysis. 13th World Conference on Earthquake Engineering. Paper no: 369, Vancouver, Canada, $15 \mathrm{p}$.

Morgenstern, N.R., Price, V.E., 1965. The analysis of the stability of general slip surfaces. Geotechnique, 15(1), 77-93..
Onions, C. T., William Little, H. W. Fowler, and J. S. Coulson, 1933. The Shorter Oxford English Dictionary. London: Oxford University Press. 2nd ed.

Sarma, S. K., 1973. Stability analysis of embankment and slopes. Geotechnique, 23(3), 423-433.

Schuster, R.L., 1996. Socio-economic significance of landslides. In: Turner, Schuster (eds.) Landslides: investigation and mitigation. TRB National Research Council Special report 247, 129-177 p.

Seed, H.B., 1979. Considerations in the earthquakeresistant design of earth and rock fill dams. Géotechnique, 29(3), 215-263.

Şengör, A.M.C., Satir, M., Akkök, R., 1984. Timing of tectonic events in the Menderes Massif, Western Turkey: implications for tectonic evolution and evidence for Pan African basement in Turkey. Tectonics, 3, 693-707.

Spencer, E.A., 1967. Method of analysis of the stability of embankments, assuming parallel interslice forces. Geotechnique, 17, 11-26.

Tarcan, G., Koca, M.Y., 2000. Hydrogeologial and geotechnical assessment of the Kadifekale landslide area, İzmir, Turkey. Environmental Geology, 40 (3), 289-299 p.

Terzaghi, K., 1950. Mechanisms of landslides. Engineering Geology (Berkeley) Volume, Geological Society of America.

TS 1900-1, 2006. İnşaat Mühendisliğinde Zemin Laboratuvar Deneyleri- Bölüm 1: Fiziksel Özelliklerin Tayini. Ankara, 99 s.

U.S. Army Corps of Engineers, 1970. Engineering and design-stability of earth and rockfill dams. Engineer Manual EM1110-2-1902. Department of the Army, Corps of Engineers, Washington D.C.

Uzel, B., Sözbilir, H., 2008. A first record of a strikeslip basin in western Anatloia and its tectonic implication: The Cumaovası Basin. Turkish Journal of Earth Sciences, 17, 559-591. 
Ulamış, Kılıç

Varnes, D.J., 1978. Slope movement types and processes. In: Schuster RL, Krizek RJ, editors. Landslides: Analysis and Control. TRB Special Report, 11-33 p.

Varnes D.J, 1984. Landslide hazard zonation-areview of principles and practice, UNESCO Press, Paris, 63 p.

WP/WLI (Working Party on world landslide inventory), 1993. A suggested method for describing the activity of a landslide. Bulletin International Association Engineering Geology, $47,53-57$
Yılmaz, Y., Genç, S.C., Gürer, F., Bozcu, M., Yılmaz, K., Karacık, Z., Altunkaynak S., Elmas, A., 2000. When did the western Anatolian grabens begin to develop? In: Bozkurt E., Winchester J.A., Piper J.D.A. (Eds.). Tectonics and magmatism in Turkey and the surrounding area, Geological Society Special Publication, no: 173. Geological Society of London. 